\title{
Merintis desa wisata, menguatkan kerjasama badan usaha milik desa dan kelompok sadar wisata
}

\author{
Haniek Listyorini", Aurilia Triani Aryaningtyas, Gana Wuntu, Renny Aprilliyani \\ Sekolah Tinggi Ilmu Ekonomi Pariwisata Indonesia (STIEPARI) Semarang \\ Email Korespondensi: "aurilia.ta@gmail.com
}

Received September 12, 2021; Revised October 5, 2021; Accepted October 6, 2021

\begin{abstract}
Abstrak
Kabupaten Kuningan Jawa Barat memiliki target menumbuhkan 25 desa wisata, dan salah satu yang sedang dirintis adalah desa wisata Cikaso Desa Kramatmulya. Dalam pembentukan desa wisata membutuhkan organisasi kelembagaan yang akan mengelola pariwisata di desa tersebut. Meskipun pemerintah telah menetapkan kelembagaan Kelompok Sadar Wisata (Pokdarwis) di desa wisata namun dalam perjalanannya pengelola masih memiliki ketidakmampuan dalam mengelola. Masalah lain adalah tidak adanya hubungan harmonis dan tumpang tindih tupoksi antara Badan Usaha Milik Desa (Bumdes) dengan Pokdarwis dalam pengelolaan rintisan desa wisata. Pokdarwis membutuhkan pendampingan bagaimana tata organisasi dapat berjalan, tupoksi masing-masing, apa saja permasalahan yang ada dalam pengembangan destinasi dan bagaimana mendapatkan dukungan dari masyarakat. Tujuan dari kegiatan pengabdian masyarakat ini adalah memperkuat kerjasama antara Bumdes dan Pokdarwis dalam rintisan suatu desa wisata. Metode yang digunakan dalam kegiatan ini meliputi ceramah, Focus Group Discussion, simulasi, dan role play lapangan.

Kata Kunci: desa wisata; kerjasama; Bumdes; Pokdarwis
\end{abstract}

\section{Abstract}

Kuningan Regency, West Java, has a target of growing 25 tourist villages. Cikaso village is one of the villages that is being pioneered into a tourist village. In developing a tourist village, an institutional organization is needed that will manage tourism in the village. Even though the government has established an institutional Tourism Awareness Group (Pokdarwis) in tourist villages, on the way the managers still have an inability to manage. Another problem is the inharmonious relationship and overlapping main tasks and functions between Corporation Effort Possession Village (Bumdes) and Pokdarwis in the management of pioneering tourism villages. Pokdarwis need assistance regarding organizational structure, main tasks and functions, as well as problems that exist in developing destinations and how to get support from the community. The purpose of this community service activity is to strengthen the collaboration between Bumdes and Pokdarwis in pioneering a tourism village. The methods used in this activity include lectures, Focus Group Discussions, simulations, and field role play.

Keywords : tourist village; cooperation; Bumdes; Pokdarwis

\section{PENDAHULUAN}

Saat ini, paket-paket wisata yang mengedepankan alam, budaya, serta sesuatu yang unik dari suatu daerah tertentu sangat diminati. Salah satu paket tersebut adalah mengunjungi desa wisata. Berdasarkan hal tersebut, pemerintah saat ini sedang gencar menggerakkan tumbuhnya ribuan desa wisata di seluruh Indonesia. Desa Wisata menjadi destinasi yang diandalkan sebagai penggerak ekonomi pariwisata dan ekonomi masyarakat khususnya pedesaan [1][2]. Namun tidak setiap desa dapat dijadikan desa wisata. Dibutuhkan potensi dan kesiapan masyarakat untuk dapat mengembangkan suatu desa wisata [3]. Desa wisata hanya dapat berkembang jika dikelola oleh desa itu sendiri. Organisasi yang khusus mengurusi desa wisata dibutuhkan agar berkelanjutan serta melibatkan pihak yang menentukan arah desa wisata [4]. Pembinaan masyarakat merupakan salah satu strategi pengembangan desa yang dapat dilaksanakan supaya satu orang dengan yang lain memiliki pemikiran yang sama [5][6].

Desa Cikaso merupakan salah satu desa di Kabupaten Kuningan Jawa Barat yang sedang dirintis menjadi desa wisata karena kaya akan wisata alam pedesaan [7]. Hal ini didukung oleh luas lahan yang dimiliki desa tersebut yaitu seluas 170,67 Ha, yang terdiri dari tanah sawah dan tanah kering. Luas tanah tersebut digunakan untuk berbagai keperluan baik sawah, perumahan, pekarangan desa, pemakaman, lapangan olah raga, dan lain-lain. Namun jenis penggunaan tanah yang paling luas adalah untuk persawahan yaitu 115,27 ha $(67,54 \%)$ dari keseluruhan luas lahan. Desa Cikaso berpenduduk sekitar 4.792 jiwa terdiri dari 1.504 kepala 
keluarga $(\mathrm{KK})$ yang sebagian besar mengelola lahan pertanian. Masyarakat lokal juga memiliki potensi berupa beragam aktivitas yang dapat dikemas menjadi produk pariwisata.

Dalam rintisan desa wisata, tentunya apa yang dimiliki tersebut harus dapat dikelola dengan baik. Hal ini diperlukan agar dapat bersaing dengan desa wisata lain yang saat ini pertumbuhannya sedang digalakkan oleh pemerintah. Untuk itu sangat dibutuhkan organisasi kelembagaan yang akan mengelola pariwisata di desa tersebut [8][9]. Di Cikaso telah dibentuk kelembagaan Kelompok Sadar Wisata (Pokdarwis). Kelompok Sadar Wisata (Pokdarwis) yaitu merupakan kelembagaan di tingkat masyarakat yang anggotanya terdiri dari para pelaku kepariwisataan yang memiliki kepedulian dan tanggung jawab serta berperan sebagai penggerak dalam mendukung terciptanya iklim kondusif bagi tumbuh dan berkembangnya kepariwisataan dan memanfaatkannya bagi kesejahteraan masyarakat sekitar [10]. Namun dalam perjalanannya, Pokdarwis yang ada masih memiliki ketidakmampuan dalam mengelola desa wisata tersebut. Belum ada kerjasama yang baik antara Pokdarwis dengan Badan Usaha Milik Desa (Bumdes) dalam tugas pokok dan fungsi (tupoksi) pengelolaan rintisan desa wisata. Masih tumpang tindihnya tupoksi antara Bumdes dengan Pokdarwis dalam pengelolaan rintisan desa wisata telah menyebabkan hubungan yang kurang harmonis. Dalam kodisi demikian, juga diperlukan penguatan dukungan dari kelompok-kelompok masyarakat dalam memperkuat kelembagaan pengelolaan rintisan desa wisata serta Peraturan Desa yang akan melindungi keberlanjutan pengembangan desa wisata [11][12]. Untuk dapat lebih menggambarkan situasi dan kondisi yang ada, dilakukan identifikasi masalah dengan menggunakan analisis SWOT yang ditunjukkan dalam tabel 1.

Tabel 1. Analisis SWOT

\begin{tabular}{ll}
\hline \multicolumn{1}{c}{ SWOT } & \\
\hline Strengths (kekuatan) & Keterangan \\
& - Likaso kaya akan wisata alam pedesaan \\
& pemandangan yang indah \\
& - Masyarakat lokal mempunyai beragam aktivitas yang dapat dikemas menjadi \\
& produk pariwisata. \\
& - Telah dibentuk kelembagaan Kelompok Sadar Wisata (Pokdarwis) \\
Weaknesses & - Pokdarwis yang ada belum mampu mengelola desa wisata secara maksimal \\
(kelemahan) & Belum ada kerjasama yang baik antara Badan Usaha Milik Desa (Bumdes) \\
& dengan Pokdarwis dalam tugas pokok dan fungsi (tupoksi) pengelolaan rintisan \\
& desa wisata. \\
Opportunities (peluang) & - Sesuatu yang unik dari suatu daerah tertentu sangat diminati wisatawan \\
& - Pemerintah saat ini sedang gencar menggerakkan tumbuhnya ribuan desa wisata \\
Threats & di seluruh Indonesia \\
(ancaman) & Banyaknya desa wisata lain yang saat ini sedang digalakkan pertumbuhanya \\
\hline
\end{tabular}

Hasil analisis SWOT menunjukkan bahwa Pokdarwis membutuhkan pendampingan mengenai tata organisasi, tupoksi masing-masing, serta apa saja permasalahan yang ada dalam pengembangan destinasi, terutama untuk mendapatkan dukungan dari masyarakat. Berdasarkan hal tersebut, maka Tim pengabdian masyarakat STIEPARI Semarang bertujuan memberikan pendampingan dalam mengatasi persoalan yang dihadapi dalam mengembangkan desa wisata Cikaso, terutama dalam penguatan kerjasama Bumdes dan Pokdarwis agar pengelolaan desa wisata dapat dilakukan dengan maksimal dan dapat bersaing dengan desa wisata yang lain.

\section{METODE}

Beberapa metode digunakan dalam kegiatan pengabdian masyarakat ini. Pelaksanaan kegiatan dibagi dalam beberapa tahap. Tahap pertama adalah sosialisasi program kegiatan dengan menggunakan metode ceramah [13]. Metode Focus Group Discussion [14] dilakukan untuk menginventarisasi permasalahan desa wisata dlm aspek Atraksi, Amenitas, Aksesibilitas, SDM, dan Kelembagaan. Dalam kegiatan ini juga dilakukan metode simulasi [15] dalam rangka mendapatkan dukungan kelompok masyarakat untuk kemajuan rintisan desa wisata. Metode role play lapangan [16] digunakan untuk mempraktikkan pengelolaan paket gowes Cikaso sebagai rintisan paket wisata. Metode ceramah dan diskusi juga digunakan dalam kegiatan penguatan kelembagaan dan hubungan kerjasama Bumdes-Pokdarwis, serta penguatan produk usaha Bumdes. Metode pendampingan dilakukan oleh Tim Pengabdian dalam penyusunan Peraturan Desa (PERDES) yang dapat melindungi keberlanjutan desa wisata.

Untuk keberhasilan kegiatan tersebut, maka disusun jadwal kegiatan yang akan dilaksanakan oleh Tim pengabdian masyarakat sebagai berikut: 
Tabel 2. Jadwal Kegiatan dan Materi

\begin{tabular}{|c|c|c|c|}
\hline No. & Hari/Tanggal & Kegiatan & Fasilitator \\
\hline 1 & $\begin{array}{l}\text { Rabu, } \\
\text { 10 Februari } 2021 \\
\text { 19.00-21.00 WIB }\end{array}$ & Sosialisasi Kegiatan & Dra. Renny Aprilliyani, M.M. \\
\hline 2 & $\begin{array}{l}\text { Kamis, } \\
11 \text { Februari } 2021 \\
08.00-12.00 \text { WIB }\end{array}$ & Roleplay Paket Gowes Cikaso & $\begin{array}{l}\text { Kelompok Karangtaruna, } \\
\text { POKDARIWS, Ibu PKK - Tim } \\
\text { Pengabdian }\end{array}$ \\
\hline 3 & $\begin{array}{l}\text { Kamis, } \\
11 \text { Februari } 2021 \\
14.00-17.00 \text { WIB }\end{array}$ & $\begin{array}{l}\text { Penguatan Kelembagaan Bumdes- } \\
\text { Pokdarwis }\end{array}$ & Haniek Listyorini, S.E., MBA. \\
\hline 4 & $\begin{array}{l}\text { Jumat, } \\
12 \text { Februari } 2021 \\
14.00-17.00 \text { WIB }\end{array}$ & $\begin{array}{l}\text { Partisipasi Kelompok Masyarakat } \\
\text { dalam Identifikasi MasalahDeswita } \\
\text { dlm aspek Atraksi,Amenitas, } \\
\text { Aksesibilitas, SDM dan Kelembagaan }\end{array}$ & $\begin{array}{l}\text { Gana Wuntu, S.E., M.M.Par. } \\
\text { Aurilia Triani A.,S.E., M.M. } \\
\text { Dra. Renny Parilliyani, M.M. } \\
\text { Haniek Listyorini, S.E., MBA. }\end{array}$ \\
\hline 5 & $\begin{array}{l}\text { Sabtu, } \\
13 \text { Februari } 2021\end{array}$ & $\begin{array}{l}\text { Penguatan hubungan Kerjasama } \\
\text { Bumdes-Pokdarwis }\end{array}$ & Gana Wuntu, S.E., M.M.Par. \\
\hline 6 & $\begin{array}{l}\text { Minggu, } 14 \text { Februari } \\
2021\end{array}$ & $\begin{array}{l}\text { Partisipasi Kelompok Masyarakat } \\
\text { dalam homestay }\end{array}$ & $\begin{array}{l}\text { Rupiningsih, S.E, M.Mpar. } \\
\text { Pranoto, S.Pd., M.Par. }\end{array}$ \\
\hline 7 & $\begin{array}{l}\text { Kamis, } \\
4 \text { Maret } 2021\end{array}$ & Penguatan Produk Usaha Bumdes & Haniek Listyorini, S.E., MBA. \\
\hline 8 & $\begin{array}{l}\text { Senin, } \\
29 \text { Maret2021 }\end{array}$ & $\begin{array}{l}\text { Penyusunan Peraturan Desa } \\
\text { (PERDES) }\end{array}$ & $\begin{array}{l}\text { Gana Wuntu, S.E, M.M.Par. } \\
\text { Pranoto, S.Pd., M.Par. }\end{array}$ \\
\hline
\end{tabular}

\section{HASIL DAN PEMBAHASAN}

a. Sosialisasi Pengabdian pada Masyarakat

Pada awal kegiatan, dilakukan ceramah dan diskusi tentang sosialisasi kegiatan pengabdian masyarakat terhadap Pokdarwis, Bumdes, Kelompok Ibu PKK dan Kelompok Karangtaruna pada Rabu, 10 Februari 2021 pukul 19.00-21.00 WIB. Rangkaian kegiatan pengabdian masyarakat disepakati sesuai jadwal. Tim pengabdian melakukan persiapan acara roleplay paket gowes cikaso (yang telah direncanakan sebelumnya melalui Focus Group Discussion dengan pertemuan zoom) sebagai sarana mempraktikkan pengelolaan paket wisata oleh Pokdarwis, ibu PKK dan karangtaruna.

\section{b. Roleplay Praktik Pengelolaan Paket Wisata Gowes Cikaso}

Hasil pertemuan dan koordinasi kemudian ditindaklanjuti dengan roleplay Paket Gowes Cikaso yang diikuti oleh 30 Peserta dengan berbagai peran. Dari kelompok STIEPARI sebanyak 15 orang, 5 orang dari kelompok masyarakat, dan 10 orang dari elemen Ibu PKK, Pokdarwis, dan Pemdes. Kelompok STIEPARI berperan sebagai wisatawan, adapun penyelenggara event adalah kelompok masyarakat pemilik sepeda gowes sebagai penyedia transportasi sepeda. Karangtaruna sebagai pemimpin perjalanan wisata, kelompok UMKM berperan sebagai penyedia atraksi edukasi pembuatan kecimpring. Ibu-ibu PKK berperan dalam menyediakan makanan dan minuman pada titik finish, serta menyediakan paket "Foto Selfie" di kawasan Sawah Lope dengan menyewakan baju Kabayan - Nyi Iteung, payung, dan caping sawah. Kegiatan roleplay dimulai dari garis start di Sawah Lope, menuju ke desa manis untuk melihat fasilitas kolam renang desa cikaso. Perjalanan gowes kemudian dilanjutkan dengan melakukan roleplay paket wisata edukasi pembuatan kecimpring. Kelompok karangtaruna juga melakukan roleplay sebagai waiter dalam menerima pesanan sewa saung dan pesan makan minum di kawasan Sawah Lope. Sebagian lagi berperan sebagai pengatur parkir dan keamanan serta penghitungan jumlah wisatawan. Kemudian Tim Pengabdian (STIEPARI) juga berperansebagai surveyor dalam menanyakan kepuasan wisatawan di Sawah Lope.

\section{c. Partisipasi Kelompok Masyarakat dalam Penguatan Pengelolaan RintisanDesa Wisata}

Dalam rangka mendapatkan inventarisasi permasalahan destinasi dalam aspek Atraksi, Amenitas, Aksesibilitas, Sumberdaya dan SDM, Tim Pengabdian mengundang elemen Pengurus Bumdes dan kelompok masyarakat yang terdiri dari Pengurus Pokdarwis, Pengurus Karangtaruna, Pengurus PKK dan kelompok UMKM. Peserta dibagi dalam 5 kelompok melakukan diskusi terhadap permasalahan yang mereka temui, dan kemudian mereka menuliskan hasil temuan identifikasi permasalahan tersebut ke dalam papan. Setiap kelompok kemudian memaparkan hasil temuan mereka serta mengajukan usulan jalan keluar dari setiap permasalahan yang ditemui. 

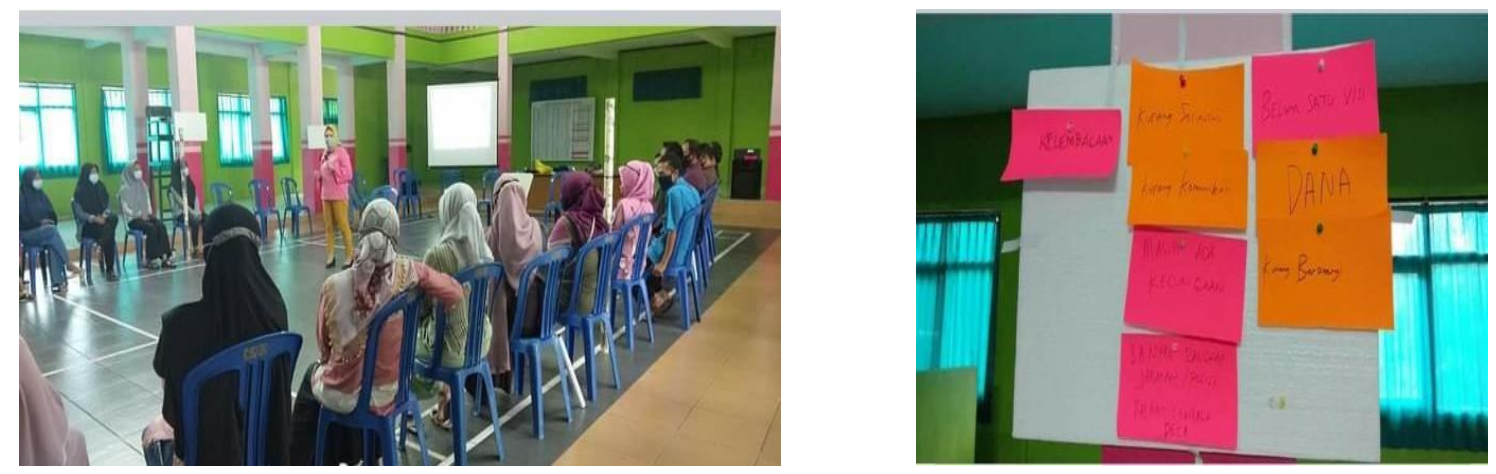

Gambar 1. FGD dan Simulasi Permasalahan 3 A, Kelembagaan, dan SDM

Kegiatan FGD ini bertujuan agar masyarakat desa wisata dapat menemukan sendiri permasalahan serta menemukan jalan keluar dalam pengembangan desa wisata di Cikaso.

Hasil diskusi kelompok dapat ditabulasikan sebagai berikut:

Tabel 3. Pemetaan Masalah Rintisan Desa Wisata

\begin{tabular}{|c|c|c|c|}
\hline No. & Kelompok & Identifikasi Permasalahan & Jalan Keluar \\
\hline 1 & Atraksi & $\begin{array}{l}\text { Belum ada atraksi budaya } \\
\text { lokal }\end{array}$ & Membuat paket Rabu Nyunda \\
\hline 2 & Amenitas & $\begin{array}{l}\text { Belum banyak homestay, } \\
\text { belum memiliki keseragaman } \\
\text { menu makan }\end{array}$ & $\begin{array}{l}\text { Menambah jumlah rumah untuk } \\
\text { homestay, menyepakati menu } \\
\text { homestay }\end{array}$ \\
\hline 3 & Aksesibilitas & Belum memiliki lahan parkir & $\begin{array}{l}\text { Menyiapkan lahan parkir di sisi } \\
\text { timur jalan Cikaso }\end{array}$ \\
\hline 4 & Kelembagaan & $\begin{array}{l}\text { Masalah Pendanaan dan } \\
\text { harmonisasi kelembagaan } \\
\text { serta partisipasi kelompok } \\
\text { masyarakat }\end{array}$ & $\begin{array}{l}\text { Mencari sumber Dana Desa, dan } \\
\text { dana modal sosial melalui iuran } \\
\text { warga. Penguatan kerjasama } \\
\text { Bumdes, Pokdarwis dan } \\
\text { kelompok-kelompok masyarakat. }\end{array}$ \\
\hline 5 & SDM & Generasi penerus & Pelatihan bagi generasi penerus \\
\hline
\end{tabular}

\section{d. Kegiatan Penguatan Kerjasama kelembagaan Bumdes- Pokdarwis}

Pengurus Pokdarwis dan pengurus Bumdes dipertemukan oleh Tim Pengabdian pada Kamis, 11 Februari 2021 pukul 14.00-17.00 WIB untuk melakukan diskusi guna memahami perbedaan persepsi tupoksi dari masing-masing pihak. Selanjutnya dilakukan kegiatan membentuk sinergitas tupoksi dari Pokdarwis dan Bumdes. Karena dalam Bumdes Cikaso terdapat bidang pariwisata, maka disarankan bahwa pengurus Pokdarwis bisa masuk menjadi pengurus Bumdes. Bumdes menjadi pemilik asset pariwisata dan Pokdarwis menjadi pengelolanya.
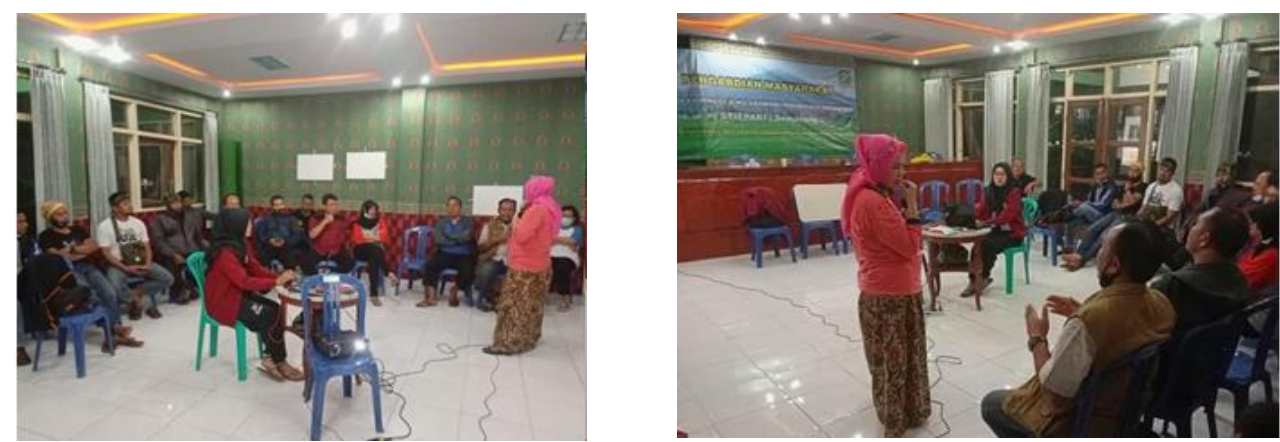

Gambar 2. Menyatukan Persepsi Bumdes dan Pokdarwis 


\section{e. Kegiatan Partisipasi Kelompok Masyarakat dalam Usaha Amenitas Homestay}

Dalam rangka memperkuat kelembagaan, didakan pertemuan dengan Ibu-Ibu PKK guna membentuk Tim Akomodasi. Sebelum kegiatan telah terdapat 2 akomodasi homestay yaitu dari rumah penduduk setempat. Pada kegiatan ini telah dapat dibentuk pengurus akomodasi homestay. Kegiatan pembinaan akomodasi dilakukan dengan memaparkan materi tentang hospitality di dalam dunia akomodasi yang meliputi keramahtamahan, syarat tata graha, dan pengelolan makan minum homestay. Dari kegiatan ini dihasilkan tambahan pratisipasi msayarakat sebagai penyedia homestay dari 2 KK dengan 6 kamar untuk 12 orang, menjadi $10 \mathrm{KK}$ yang dapat menampung 50 wisatawan.
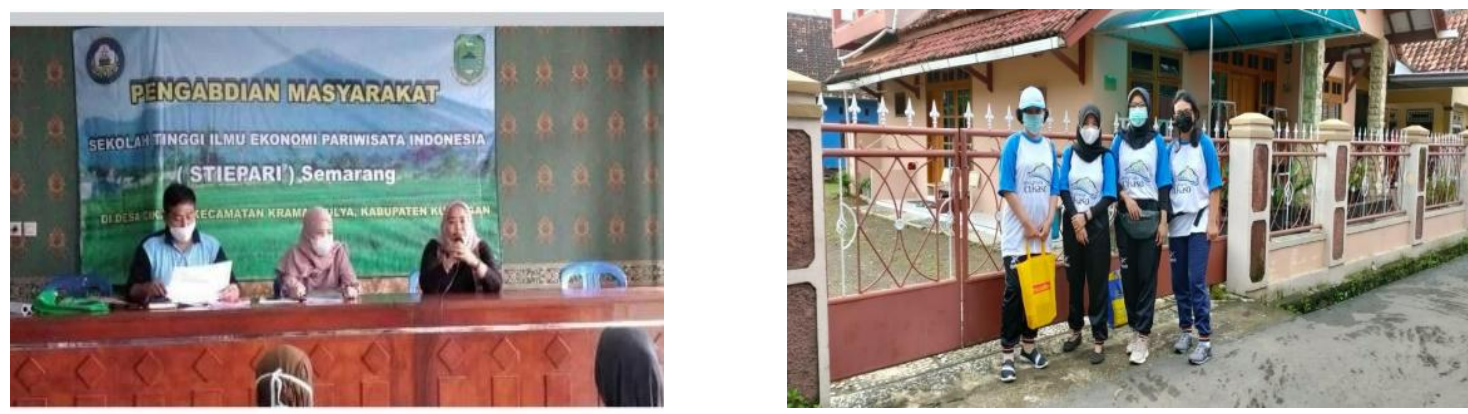

Gambar 3. Pembinaan Homestay dan Contoh Homestay

\section{f. Kegiatan Penguatan Produk Usaha Bumdes}

Dalam rangka mendukung dunia usaha Bumdes Cikaso, maka Tim telah menyerahkan 2 paket bibit ikan Koi yang diserahkan kepada Kepala Desa Bapak Hidayat, M.M. di area kolam renang Desa Cikaso. Acara dilanjutkan dengan penguatan kelembagaan dari DPRD Jawa Barat Ibu Tina dengan rencana untuk menyelenggarakan pelatihan bagi Porkdarwis dan Bumdes di Desa Cikaso, Kabupaten Kuningan.

\section{g. Kegiatan Penyusunan PERDES Cikaso}

Untuk melindungi keberlanjutan desa wisata, sangat diperlukan penyusunan Peraturan Desa (PERDES). Dalam penyusunan PERDES, kegiatan yang dilakukan tim pendamping adalah berinisiatif mengadakan pertemuan dengan kelembagaan masyarakat dan pemerintah desa untuk membahas tentang pentingnya sebuah desa memiliki peraturan desa. Dalam banyak kasus, pengembangan desa wisata dapat bertentangan dengan nilai-nilai keberlanjutan dan bermasalah dengan Bumdes. Dalam hal ini, Tim pengabdian berperan dalam mendorong, memberikan konsultasi, mendampingi dalam forum rapat penyusunan Draft Perdes, serta ikut mengawal pembentukan PERDES tersebut.

Kewenangan penyusunan PERDES ada pada unsur-unsur di dalam desa Cikaso. Pada rapat pertama tanggal 29 Maret 2021, agendanya melakukan pengumpulan aspirasi dari masyarakat melalui perwakilan kelembagaan yang diundang kemudian menyusun arah kebijakan dan agenda yang akan dibahas pada pertemuan selanjutnya. Tim pengabdian memberikan pandangan dan best practice dari berbagai kasus yang sudah ada sebelumnya, serta referensi yang diperlukan untuk penyusunan Perdes tersebut. Tim Pengabdian melakukan pendampingan selama proses penyusunan baik dilakukan dalam forum rapat resmi maupun secara informal untuk menambah referensi yang dibutuhkan. Hal tersebut dilakukan dengan komunikasi secara online sebanyak empat kali. Pada rapat-rapat dihadiri oleh Pemerintah Desa, Badan Perwakilan Desa, Pokdarwis, Bumdes, Karang Taruna, Para Ketua Dusun, Tokoh masyarakat Cikaso dan Tim Pengabdian.

Hasil pendampingan ini diharapkan dapat memperkuat keberlanjutan desa wisata karena telah sesuai dengan koridor dalam Perdes. Pada bulan Juli telah memasuki tahap pembahasan ke-4, dengan agenda perubahan pasal-pasal setelah melakukan studi banding dengan desa wisata lain di Kuningan. Diharapkan pada akhir Juli Perdes sudah dapat ditetapkan.
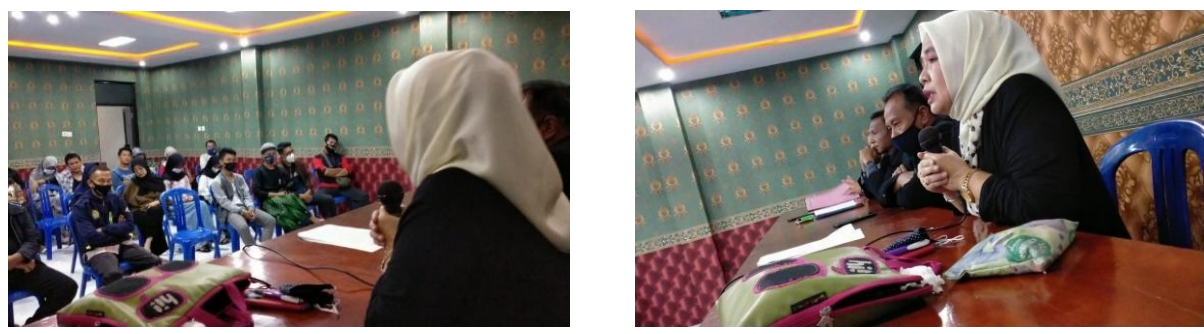

Gambar 4. Pendampingan Penyusunan PERDES Cikaso 


\section{h. Evaluasi hasil kegiatan} berikut:

Pada akhir kegiatan, diadakan evaluasi hasil kegiatan terhadap 21 peserta kegiatan dengan hasil sebagai

Tabel 4. Rangkuman Tanggapan Peserta terhadap Pemahaman Tupoksi Pokdarwis Bumdes

\begin{tabular}{lcc}
\hline \multicolumn{1}{c}{ Tingkat Pemahaman } & Jumlah & Persentase \\
\hline Sangat paham & 16 & $76 \%$ \\
Paham & 5 & $24 \%$ \\
Tidak Paham & 0 & $0 \%$ \\
Jumlah & 21 & $100 \%$ \\
\hline
\end{tabular}

Dari tabel di atas, dapat diketahui bahwa 16 peserta (76\%) menyatakan 'sangat paham' terhadap materi yang diberikan terkait Tupoksi Pokdarwis dan Bumdes, 5 peserta (24\%) menyatakan 'paham', serta tidak ada yang menyatakan 'tidak paham'.

Tabel 5. Rangkuman Tanggapan Peserta terhadap Peningkatan kemampuan Pokdarwis dan KelompokKelompok Masyarakat Dalam Mengelola Paket Wisata

\begin{tabular}{lcc}
\hline \multicolumn{1}{c}{ Peningkatan Kemampuan } & Jumlah & Persentase \\
\hline Sangat meningkat & 14 & $67 \%$ \\
Cukup meningkat & 7 & $33 \%$ \\
Tidak meningkat & 0 & $0 \%$ \\
Jumlah & 21 & $100 \%$ \\
\hline
\end{tabular}

Adapun tanggapan peserta terhadap peningkatan kemampuan dalam mengelola paket wisata adalah 14 peserta (67\%) merasakan kemampuan yang 'sangat meningkat', 7 peserta (33\%) merasakan 'cukup ada peningkatan' kemampuan, serta tidak ada yang menyatakan 'tidak ada peningkatan' sama sekali.

Tabel 6. Tanggapan Peserta terhadap Keberhasilan Penyusunan Perdes

\begin{tabular}{lcc}
\hline \multicolumn{1}{c}{ Tingkat Keberhasilan } & Jumlah & Persentase \\
\hline Sangat berhasil & 19 & $90 \%$ \\
Cukup berhasil & 2 & $10 \%$ \\
Tidak berhasil & 0 & $0 \%$ \\
Jumlah & 21 & $100 \%$ \\
\hline
\end{tabular}

Hasil lain menunjukkan 19 peserta (90\%) merasakan penyusunan Perdes yang dilakukan 'sangat berhasil', sedangkan sisanya yaitu 2 peserta (10\%) merasa Penyusunan Perdes 'cukup berhasil'. Tidak ada satu pun peserta yang menyatakan 'tidak berhasil' dalam menyusun Perdes. Perdes yang telah disusun tinggal menunggu penetapannya.

\section{KESIMPULAN}

Hasil dari kegiatan pengabdian kepada masyarakat ini antara lain telah terjadi pemahaman tupoksi dengan jelas antara tugas Pokdarwis dan tugas Bumdes, sehingga dapat bersinergi dan saling mendukung. Hal ini dibuktikan dengan adanya peningkatan kemampuan Pokdarwis, Bumdes, dan kelompok-kelompok masyarakat dalam mengelola paket wisata berbasis kerjasama antar kelompok masyarakat dan pengelola Desa Wisata. Salah satu contohnya adalah pengelolaan "Paket Wisata Gowes" yang mulai ditawarkan kepada wisatawan dan tersedianya homestay untuk menambah lama tinggal wisatawan di Cikaso. Selain itu Tim pengabdian berhasil membantu desa dalam menyusun PERDES yang segera akan ditetapkan untuk menjadi acuan dalam pengembangan desa wisata berbasis asset desa.

\section{DAFTAR PUSTAKA}

[1] I. N. D. Putra and I. G. Pitana, Pariwisata Pro-Rakyat: Meretas Jalan Mengentaskan Kemiskinan di Indonesia. Kementerian Kebudayaan dan Pariwisata, 2010.

[2] D. Yustina, E. Rahayu, R. Aprilliyani, and A. T. Aryaningtyas, "Penguatan Kelompok Ibu-Ibu PKK dalam Usaha Produk Beauty Spa guna Mendukung Rintisan Desa Wisata," JMM (Jurnal Masyarakat Mandiri), vol. 5, no. 2, pp. 526-538, 2021.

[3] S. I. P. Barus, P. Patana, and Y. Afifuddin, "Analisis Potensi Obyek Wisata dan Kesiapan Masyarakat dalam Pengembangan Desa Wisata Berbasis Masyarakat di Kawasan Danau Linting Kabupaten Deli Serdang," Peronema Forestry Science Journal, vol. 2, no. 2, pp. 143-151, 2013. 
[4] N. R. Yudhasesa, I. Aliyah, and G. Yudana, "Pengaruh Jejaring Industri Lurik terhadap Pengembangan Desa Wisata Tenun Tradisional Tlingsing, Klaten," Region: Jurnal Pembangunan Wilayah dan Perencanaan Partisipatif, vol. 15, no. 2, pp. 243-261, 2020.

[5] F. Syah, "Strategi Mengembangkan Desa Wisata," Prosiding Seminar Nasional Multi Disiplin Ilmu \& Call For Papers Unisbank ke-3 (SENDI_U 3), 2017.

[6] A. T. Aryaningtyas and A. D. M. Th, "Pembinaan Pengelola Usaha Daya Tarik Wisata di Jawa Tengah: Sosialisasi Standar Usaha," KACANEGARA Jurnal Pengabdian pada Masyarakat, vol. 4, no. 1, pp. 59-64, 2021.

[7] A. T. Aryaningtyas and Y. D. Risyanti, "Empowerment of Local Plants as Beauty Products to Increase MSME Income," Enrichment: Journal of Management, vol. 12, no. 1, pp. 278-282, 2021.

[8] I. Junaid and M. A. M. Salim, "Peran Organisasi Tata Kelola dalam Pengelolaan Desa Wisata Nglanggeran, Yogyakarta," PUSAKA: Journal of Tourism, Hospitality, Travel and Business Event, 2019.

[9] G. R. Prafitri and M. Damayanti, "Kapasitas Kelembagaan dalam Pengembangan Desa Wisata (Studi Kasus: Desa Wisata Ketenger, Banyumas)," Jurnal Pengembangan Kota, vol. 4, no. 1, pp. 76-86, 2016.

[10]---, Pedoman Kelompok Sadar Wisata. Jakarta: Direktur Jenderal Pengembangan Destinasi Pariwisata Kementrian Pariwisata dan Ekonomi Kreatif, 2012.

[11] M. Isa and A. N. Praswati, "Penguatan Kelembagaan Desa Wisata Kreatif Kenep Sukoharjo," Prosiding Seminar Bisnis Magister Manajemen (SAMBIS), 2019.

[12] D. P. O. Prasiasa and D. A. D. S. Widari, "Desa Wisata Berbasis Pemberdayaan, Kemitraan, dan Penguatan Kelembagaan di Desa Terunyan, Bali," Jurnal Sosiologi USK (Media Pemikiran \& Aplikasi), vol. 13, no. 1, pp. 55-71, 2019.

[13] A. L. Behr, "Exploring the Lecture Method: an Empirical Study," Studies in Higher Education, vol. 13, no. 2, pp. 189-200, 1988.

[14] Y. Afiyanti, "Focus Group Discussion (Diskusi Kelompok Terfokus) sebagai Metode Pengumpulan Data Penelitian Kualitatif," Jurnal Keperawatan Indonesia, vol. 12, no. 1, pp. 58-62, 2008.

[15]A. V. Galaresa and S. Sundari, "Penggunaan Metode Simulasi dalam Peningkatan Critical Thinking: Literature Review," Jurnal Penelitian Keperawatan, vol. 5, no. 1, 2019.

[16] B. J. Brummel, C. K. Gunsalus, K. L. Anderson, and M. C. Loui, "Development of Role-Play Scenarios for Teaching Responsible Conduct of Research," Science and Engineering Ethics, vol. 16, no. 3, pp. 573-589, 2010. 
